\title{
COMPORTAMENTO DA INTERFACE METAL/ESCÓRIA EM MOLDE DE BEAM BLANK*
}

\author{
Weslei Viana Gabriel ${ }^{1}$ \\ Johne Jesus Mol Peixoto ${ }^{1}$ \\ Gesiane Letícia Alves ${ }^{2}$ \\ Carlos Antonio da Silva ${ }^{3}$ \\ Itavahn Alves da Silva ${ }^{3}$ \\ Varadarajan Seshadri ${ }^{4}$
}

\section{Resumo}

Utilizando um sistema composto por solução aquosa e óleo como substitutos do metal e da escória, respectivamente, foram realizadas simulações físicas e matemáticas em molde de beam blank, de maneira a avaliar efeito da diferença de densidade entre os fluidos, viscosidade do óleo, velocidade de lingotamento e profundidade de imersão da válvula submersa. O aumento da velocidade de lingotamento resulta em aumento da velocidade na interface, bem como a oscilação da superfície livre. Para a densidade de solução aquosa igual a $1000 \mathrm{~kg} / \mathrm{m}^{3}$ observou-se entranhamento de óleo a partir da velocidade de $0,98 \mathrm{~m} / \mathrm{min}$. Ao se aumentar a densidade da solução para $1170 \mathrm{~kg} / \mathrm{m}^{3}$ não se observou entranhamento em nenhuma das condições estudadas..

Palavras-chave: Lingotamento Contínuo; Válvula Submersa; Beam Blank; interface metal-escória.

\section{BEHAVIOR OF THE SLAG-METAL INTERFACE IN A BEAM BLANK MOLD}

\begin{abstract}
Physical and mathematical simulations of fluid flow inside a beam blank mold with aqueous solution and oil emulating metal and slag, respectively, have been performed in order to evaluate the effects of the density difference, viscosity of the oil, casting velocity and nozzle immersion depth. Increasing the casting velocity leads to increasing interface velocity and oscillation intensity. Oil entrapment was observed under all tested conditions with aqueous solution of $1000 \mathrm{~kg} / \mathrm{m}^{3}$ density. No entrapment was with a aqueous solution of $1170 \mathrm{~kg} / \mathrm{m}^{3}$ density.
\end{abstract}

Keywords: Continuous Casting; SEN; Beam Blank; slag-metal interface.

1 Engenheiro Metalurgista, Doutorando em Engenharia de Materiais/REDEMAT, Universidade Federal de Ouro Preto, Minas Gerais Brasil.

2 Graduando em Metalurgia, Escola de Minas, Ouro Preto, Minas Gerais, Brasil..

3 Engenheiro Metalurgista, Ph.D., Professor, Universidade Federal de Ouro Preto, Escola de Minas, Ouro Preto, Minas Gerais, Brasil..

4 Engenheiro Metalurgista, Dr.Ing., Professor Emérito, Universidade Federal de Minas Gerais, Belo Horizonte, Minas Gerais, Brasil. 


\section{INTRODUÇÃO}

O fenômeno de entranhamento de escória, em moldes de lingotamento contínuo, consiste de cisalhamento na interface metal/escória e arraste de parcelas de escória líquida da camada de pó fluxante para a poça de aço. O aprisionamento destas gotículas de escória durante o processo de solidificação implica em redução na limpidez do metal gerando, portanto, produtos com maior número de defeitos tanto superficiais quanto internos. Segundo Hibbeler et al. [1], padrões de fluxo cujo jato é direcionado para a parte inferior do molde aumentam a probabilidade das inclusões serem aprisionadas pela frente de solidificação; fluxos direcionados à camada de escória aumentam a probabilidade de entranhamento da mesma.

O entranhamento de escória de cobertura é uma importante fonte de inclusões superiores a $20 \mu \mathrm{m}$ (Cramb et al. [2]). Tanto o controle de fluxo quanto da composição química da escória são formas de se controlar a emulsificação. Deng et al. [3] relatam que as alterações no padrão de fluxo geradas pelo campo magnético afetam o comportamento da interface metal/escória.

Dentre os fenômenos que explicam o entranhamento de escória podem-se destacar os redemoinhos, alta velocidade do fluido que cisalha a interface metal-escória e turbulência na região do menisco (Thomas [4]). A velocidade do fluido na região da interface a partir da qual ocorre o entranhamento é definida como velocidade crítica. O seu valor depende de características geométricas tanto do molde, quanto da válvula, espessura da camada de escória, bem como das propriedades do metal e da escória, dentre elas: tensão interfacial, densidade, viscosidade.

Simulações físicas da interação metal-escória são desafiantes por causa da dificuldade de se encontrar materiais cujas relações entre as propriedades sejam semeIhantes às do metal e escória líquidos. Normalmente, a água é utilizada para a simulação do metal, enquanto óleos de silicone simulam a escória. A diferença de densidade entre água e óleo é em torno de $5 \%$, enquanto que a densidade da escória corresponde a aproximadamente $35 \%$ da densidade do aço. Sendo assim, resultados de simulação física não refletem exatamente os reais. Por isto, é comum a utilização de diferentes materiais, de modo a prever a variação do comportamento interfacial quando variam-se as propriedades físicas dos fluidos envolvidos (Scheller e Hagemann [5]).

Por meio da adição de sais na água é possível aumentar a densidade da mesma e consequentemente avaliar o efeito da diferença de densidade na velocidade crítica de entranhamento. Existem procedimentos experimentais citados na literatura em que se utilizou cloreto de sódio, aumentando a densidade da água para até $1170 \mathrm{~kg} / \mathrm{m}^{3}$ (Savolainen et al. [6]) e carbonato de potássio em que se atingiu densidade de aproximadamente $1400 \mathrm{~kg} / \mathrm{m}^{3}$ (Harman e Cramb [7]).

Este trabalho tem como objetivo avaliar o comportamento da interface entre dois fluidos imiscíveis presentes em molde de beam blank, que representam metal e escória, verificando a influência da viscosidade, diferença de densidade, tensão interfacial, bem como de parâmetros operacionais como vazão de fluido e profundidade de imersão da SEN. 


\section{MATERIAIS E MÉTODOS}

As análises, via modelagem física, foram realizadas num molde de beam blank construído em acrílico escala 1:1 cujas dimensões são $499 \mathrm{mmX} 415 \mathrm{mmX125mm} \mathrm{e}$ $1,5 \mathrm{~m}$ de altura. Foram realizadas filmagens da interface entre os fluidos na posição apresentada na figura 1. A oscilação da superfície livre foi mensurada utilizando sensor ultrassônico modelo SICK UM30-21_118, e os pontos escolhidos para análise também estão representados na figura 1. O modelo de válvula submersa utilizada consiste de três portas laterais na saída (Figura 1 e Figura 2b). As vazões de fluido analisadas foram $100 \mathrm{~L} / \mathrm{min}, 125 \mathrm{~L} / \mathrm{min}$ e $150 \mathrm{~L} / \mathrm{min}$, que equivalem às velocidades de lingotamento de $0,78 \mathrm{~m} / \mathrm{min}, 0,98 \mathrm{~m} / \mathrm{min}$ e $1,2 \mathrm{~m} / \mathrm{min}$, respectivamente. As profundidades de imersão da SEN foram $200 \mathrm{~mm}$ e $250 \mathrm{~mm}$.

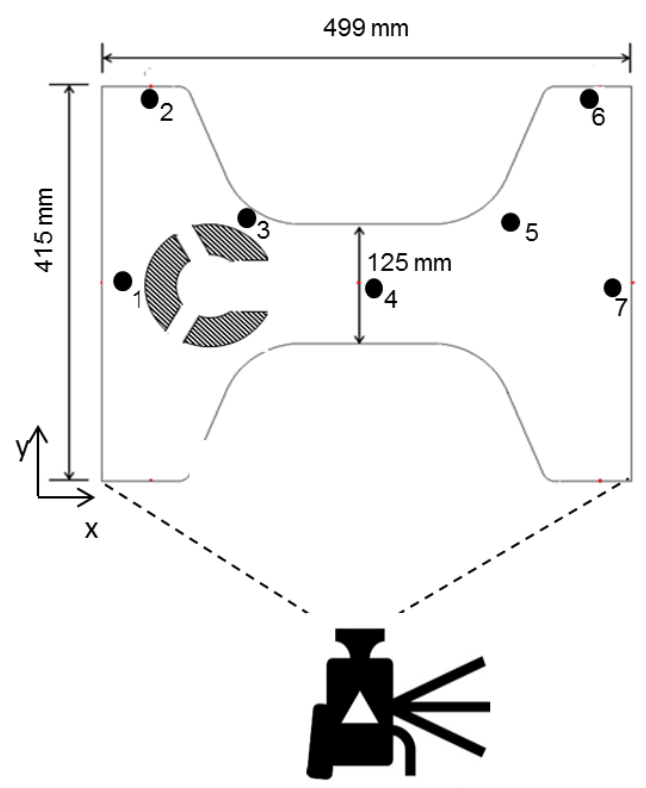

Câmera

Figura 1 Seção transversal do molde de beam blank, destacando os pontos de monitoramento da oscilação superficial, bem como as regiões de filmagem da interface entre os fluidos.

Nas simulações físicas, algumas simplificações foram realizadas. A solidificação de aço, o consumo específico de escória e a conicidade do molde foram desconsiderados, de modo a analisar somente a influência do fluxo de fluido bem como as propriedades físicas dos fluidos envolvidos para simular as interações entre os fluidos imiscíveis que simulam o aço e a escória no estado líquido.

Os fluidos utilizados para simular o aço foram água e uma solução salina. Uma camada de óleo com $20 \mathrm{~mm}$ de espessura simulou a escória líquida. As propriedades físicas dos fluidos aplicados estão apresentadas na tabela 1. Como limitações da modelagem física, destaca-se o fato de que a relação entre as propriedades físicas água/óleo não coincidem com a relação entre as propriedades aço/escória. Um exemplo é a diferença de densidade. Óleos de silicone possuem densidade em torno de $95 \%$ da densidade da água, enquanto que a densidade da escória é em torno de $35 \%$ da densidade do aço. 
Variar as propriedades dos fluidos, durante simulações de fenômenos interfásicos, permite avaliar a influência de cada propriedade individualmente, e com isto melhorar a estimativa dos fenômenos que irão ocorrer industrialmente. A utilização da solução salina permite avaliar principalmente a influência da densidade sobre os fenômenos interfásicos, enquanto, as alterações no tipo de óleo aplicado preveem principalmente a influência da viscosidade, já que ambos os óleos possuem a mesma densidade.

Tabela 1 Propriedades dos fluidos utilizados nas simulações.

\begin{tabular}{|l|c|}
\hline \multicolumn{1}{|c|}{ Propriedades } & Valor (UND) \\
\hline Densidade da água & $1000\left(\mathrm{~kg} / \mathrm{m}^{3}\right)$ \\
\hline Viscosidade da água & $0,00088(\mathrm{~Pa}$ s $)$ \\
\hline Densidade da solução salina & $1170\left(\mathrm{~kg} / \mathrm{m}^{3}\right)$ \\
\hline Viscosidade da solução salina & $0,00156(\mathrm{~Pa} \mathrm{~s})$ \\
\hline Densidade do óleo 1 & $950\left(\mathrm{~kg} / \mathrm{m}^{3}\right)$ \\
\hline Densidade do óleo 2 & $950\left(\mathrm{~kg} / \mathrm{m}^{3}\right)$ \\
\hline Viscosidade do óleo 1 & $0,475\left(\mathrm{~Pa}{ }^{*} \mathrm{~s}\right)$ \\
\hline Viscosidade do óleo 2 & $0,19(\mathrm{~Pa} \mathrm{~s})$ \\
\hline Tensão interfacial água-óleo1 & $0,0357(\mathrm{~N} / \mathrm{m})$ \\
\hline Tensão interfacial água-óleo2 & $0,0337(\mathrm{~N} / \mathrm{m})$ \\
\hline Tensão interfacial solução salina-óleo1 & $0,0401(\mathrm{~N} / \mathrm{m})$ \\
\hline Tensão interfacial solução salina-óleo2 & $0,0397(\mathrm{~N} / \mathrm{m})$ \\
\hline
\end{tabular}

\subsection{Simulação Matemática}

As simulações matemáticas foram realizadas utilizando o software Ansys CFX 17.1, considerando o regime permanente. Embora os fenômenos interfaciais sejam de natureza transiente, estudos mostraram que simulações em regime permanente permitem a avaliação dos principais parâmetros, além de economizar o tempo de simulação (Nadalon [8]).

O modelo aplicado foi o $\mathrm{k}-\epsilon$, no qual se resolve as equações da continuidade, de Navier Stokes e da Viscosidade efetiva, além das equações auxiliares para determinação de $\mathrm{k}$ (energia de turbulência) e $\epsilon$ (taxa de dissipação de energia cinética).

A primeira etapa na elaboração da simulação consistiu no desenvolvimento da geometria através do software Design Modeler do Ansys. As dimensões correspondem às do modelo físico. Em seguida, vem a geração de malha através do software Meshing Modeler. Em grande parcela do molde o elemento de malha utilizado foi o tetraédrico. Na região acima das portas de saída da válvula optou-se pela hexaédrica. Através do comando sweep foi possível um refinamento maior na região da interface óleo/água (vide figura 2a). O tamanho médio dos elementos de malha foi de $7 \mathrm{~mm}$. Sendo que na interface, em virtude do refinamento os elementos foram inferiores a $1 \mathrm{~mm}$. A malha final teve 480.000 nós e 1.220 .000 elementos. Os cálculos foram realizados na metade do molde devido às condições de simetria.

As condições de contorno aplicadas foram as seguintes:

- Entrada: Vazão mássica - para a água: 0,83kg/s, 1,041 kg/s e $1,25 \mathrm{~kg} / \mathrm{s}$ e para a solução salina: 0,97 kg/s, 1,22 kg/s e 1,46 kg/s. estas vazões corres- 
pondem às velocidades de lingotamento de $0,78 \mathrm{~m} / \mathrm{min}, 0,98 \mathrm{~m} / \mathrm{min}$ e $1,2 \mathrm{~m} / \mathrm{min}$ respectivamente.

- Saída: opening, controlado por pressão na saída.

- Superfície livre: parede com livre deslizamento.

- Paredes: condição de não deslizamento.

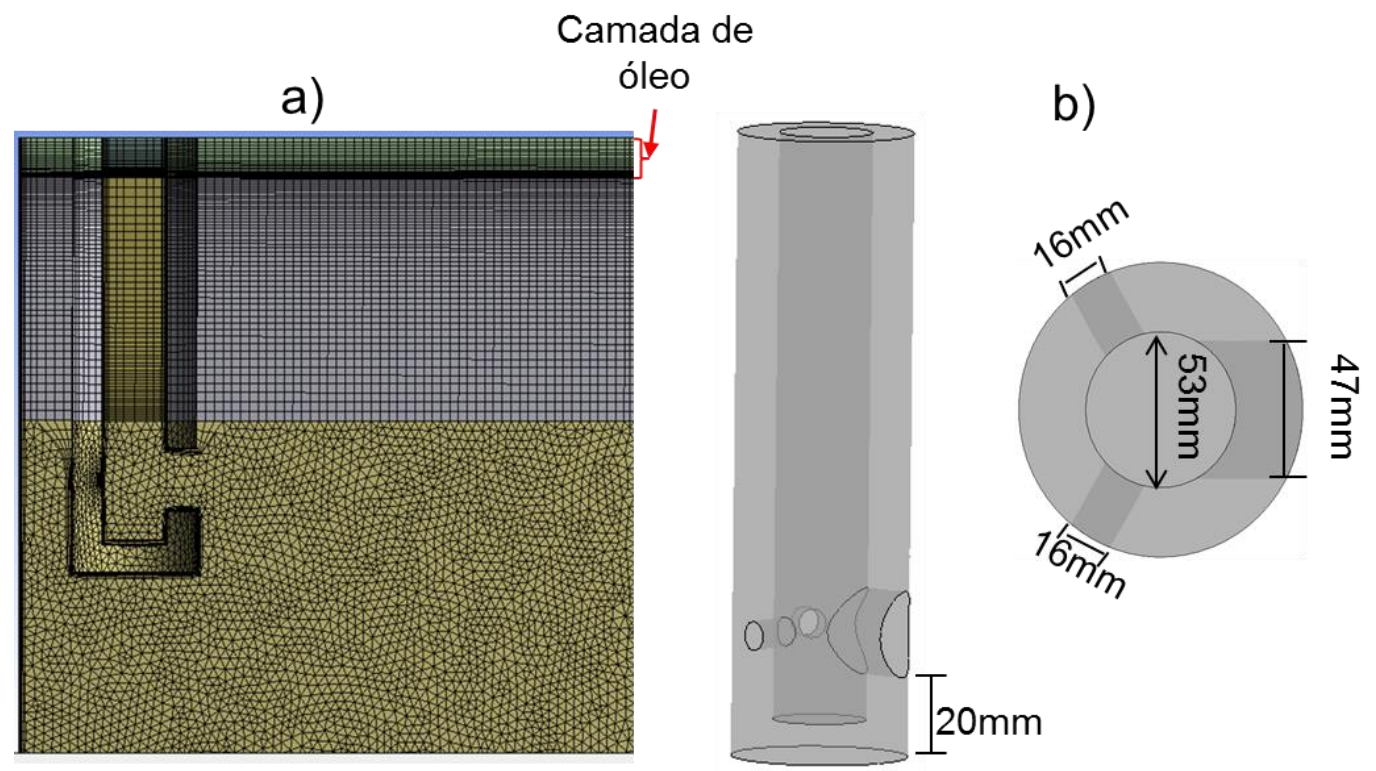

Figura 2 a) Malha construída para a simulação. b) Modelo de válvula submersa utilizado.

\section{RESULTADOS E DISCUSSÃO}

A figura 3 apresenta detalhes da interface água-óleo ao longo do molde, comparando a influência da velocidade de lingotamento e da viscosidade. Nota-se que quando aumenta a velocidade de lingotamento, há maior entranhamento de óleo na poça que emula o aço líquido. Para as vazões de 100 e 125L/min não se percebe alterações significativas na interface variando a viscosidade do óleo, enquanto que para a maior vazão, o arraste do óleo com menor viscosidade foi maior, ocasionando maior abertura de olho na região do flange oposto. Para o óleo de 500cSt a abertura de olho foi apenas nas quinas do flange oposto à válvula.
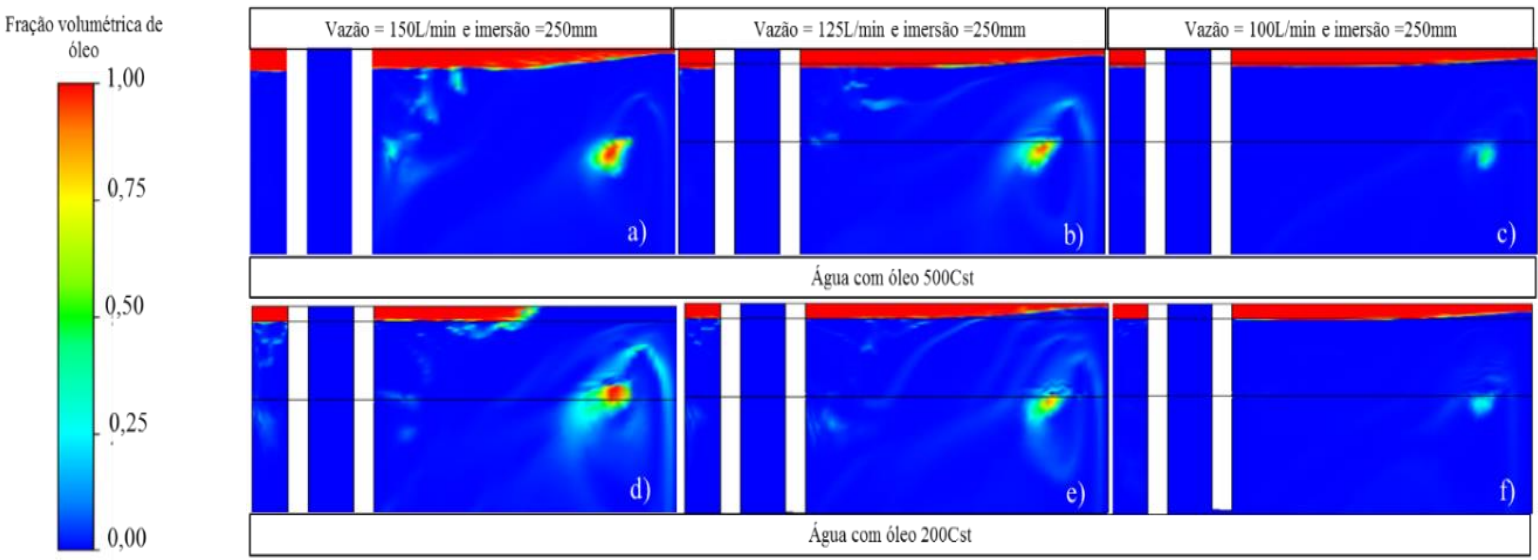

Figura 3 Análise da interface água-óleo em função da vazão e da viscosidade do óleo. a), b) e c) óleo 500 cst, d), e) e f) óleo 200cSt. 
A figura 4 apresenta a interface água-óleo 500cst para diferentes vazões e tempo. Para a vazão de 100L/min não foi observada a ocorrência de entranhamento do líquido. Comparando a figura $4 \mathrm{com}$ a 3 observa-se uma boa concordância nos aspectos interfaciais obtidos por simulação computacional e física.

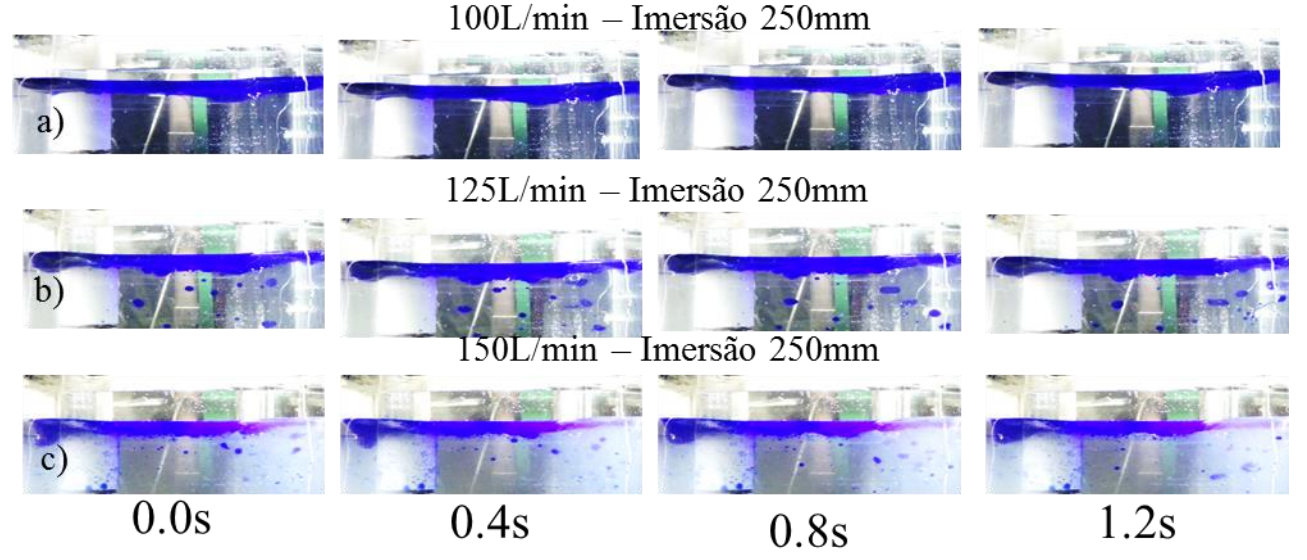

Figura 4 interface água-óleo 500cSt obtidas via simulação física para diferentes vazões a)100L/min, b) $125 \mathrm{~L} / \mathrm{mi} \mathrm{e} \mathrm{c)} 150 \mathrm{~L} / \mathrm{min}$.

Testes, via simulação física para o óleo com viscosidade 200cSt, também apresentaram entranhamento para as vazões de 125 e 150L/min. A figura 5 apresenta detaIhes da interface água-óleo 200cSt para diferentes vazões e tempo. Percebe-se que para a vazão inferior ocorre pouca deformação da interface e que próximo ao filete inicia-se a formação de um pedúnculo, porém não ocorreu desprendimento do mesmo. Para as vazões superiores, observou-se o desprendimento de gotas de óleo principalmente nesta região. Para a vazão de 150L/min nota-se uma diferença na interface água-óleo $200 c S t$ entre os resultados de simulação física e matemática, uma vez que na primeira houve um maior arraste do óleo para a região da alma. Já nas demais condições, pôde-se observar uma boa concordância entre os resultados.

$100 \mathrm{~L} / \mathrm{min}$ e imersão $=250 \mathrm{~mm}$

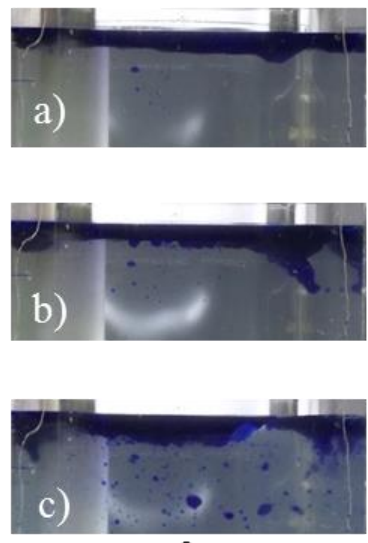

0 s

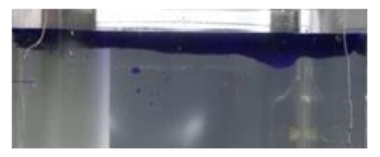

$125 \mathrm{~L} / \mathrm{min}$ e imersão $=250 \mathrm{~mm}$

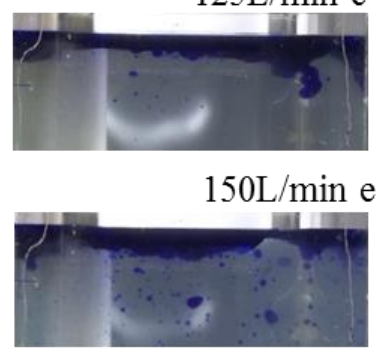

$0.4 \mathrm{~s}$

$0.8 \mathrm{~s}$
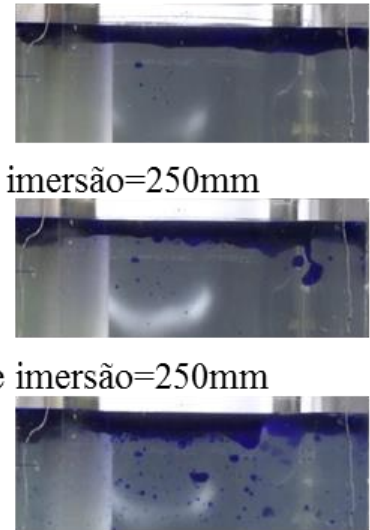
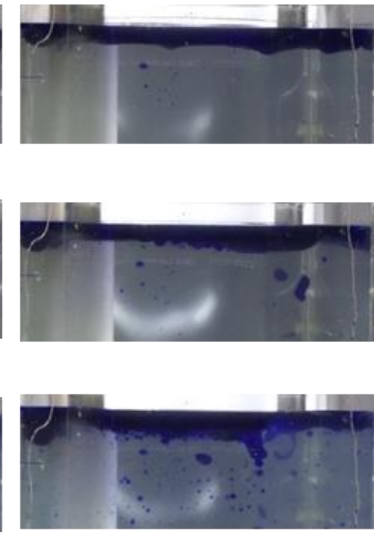

$1.2 \mathrm{~s}$

Figura 5 Interface água-óleo 200cSt obtidas via simulação física para diferentes vazões a)100L/min, b) $125 \mathrm{~L} / \mathrm{mi} \mathrm{e} \mathrm{c)} 150 \mathrm{~L} / \mathrm{min}$.

Para avaliar o efeito da densidade sobre os fenômenos interfaciais, substituiu-se a água por uma solução contendo $\mathrm{NaCl}$ com densidade de $1170 \mathrm{~kg} / \mathrm{m}^{3}$. A figura 6 apresenta a interface solução-óleo 500 cSt para as diferentes vazões. Percebe-se que não ocorreu entranhamento de óleo mesmo quando se reduziu a profundidade 
de imersão para 200mm com a maior vazão, de 150L/min. Com base nesta análise, espera-se que nas mesmas condições operacionais não ocorra entranhamento no equipamento industrial uma vez que a diferença de densidade entre escória e aço é superior à entre a solução e o óleo. Isto pode possibilitar trabalhar com uma profundidade de imersão menor, fato importante para o desenvolvimento da casca solidificada.

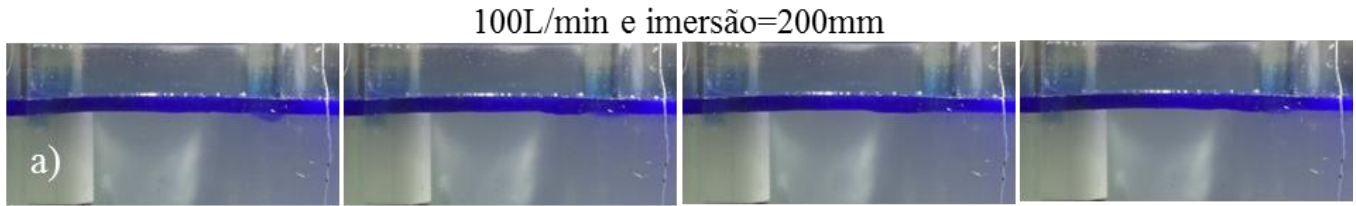

$125 \mathrm{~L} / \mathrm{min}$ e imersão $=200 \mathrm{~mm}$

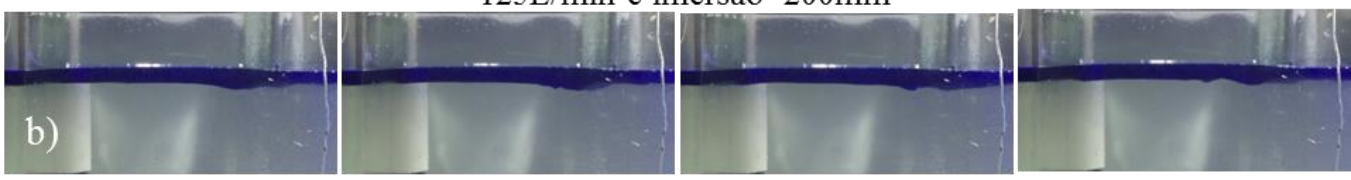

$150 \mathrm{~L} / \mathrm{min}$ e imersão $=200 \mathrm{~mm}$

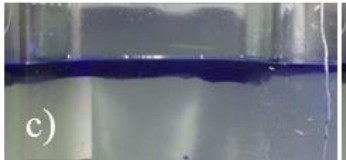

$0.0 \mathrm{~s}$

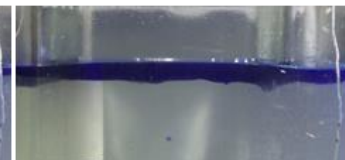

$0.4 \mathrm{~s}$

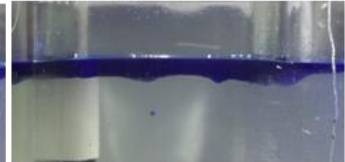

$0.8 \mathrm{~s}$

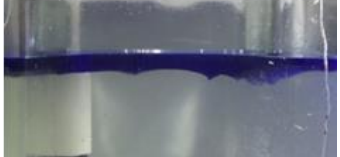

$1.2 \mathrm{~s}$

Figura 6 Interface solução aquosa de $\mathrm{NaCl}$-óleo $500 \mathrm{cSt}$ a), b) e c) profundidade de imersão = $250 \mathrm{~mm}, \mathrm{c}), \mathrm{d}$ ) e e) profundidade de imersão $=200 \mathrm{~mm}$

As análises computacionais também apresentaram resultados semelhantes. A figura 7 mostra a interface solução $\mathrm{NaCl}$-óleo $500 \mathrm{cSt}$, na qual percebe-se que praticamente não há oscilação na interface.

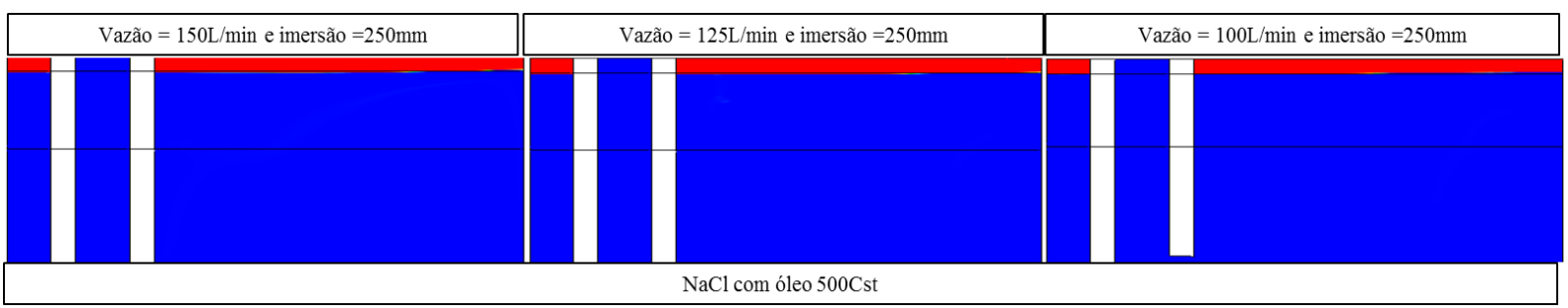

Figura 7 Análise da interface água-óleo em função da vazão, sistema água-óleo 500cSt

Com relação à intensidade de oscilação na superfície livre, os maiores valores são encontrados na região próxima ao flange oposto à válvula, sendo o valor máximo encontrado nas quinas (posição 6). Esta é a região na qual primeiramente observouse abertura de "olho". Quando se reduz a viscosidade do óleo há aumento na intensidade de flutuação (Figura 8a) e 8b)). O aumento da densidade do fluido utilizado para simular o aço e da profundidade de imersão da SEN reduz a intensidade de oscilação na superfície livre (Figura 8c) e 8d)). 

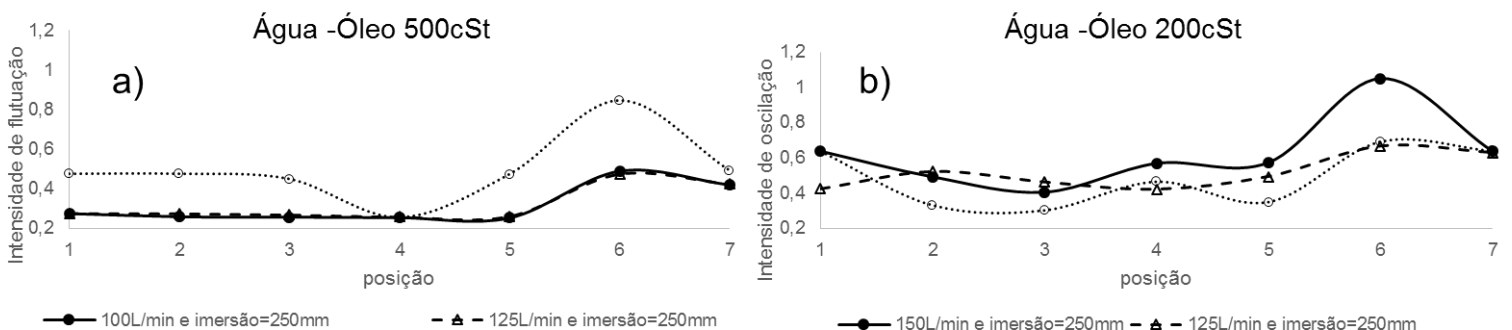

....... 150L/min e imersão= $250 \mathrm{~mm}$

$-\star-125 \mathrm{~L} / \mathrm{min}$ e imersão=250 $\mathrm{mm}$

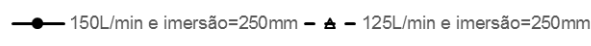
…..... 100L/min e imersão= $250 \mathrm{~mm}$

c)

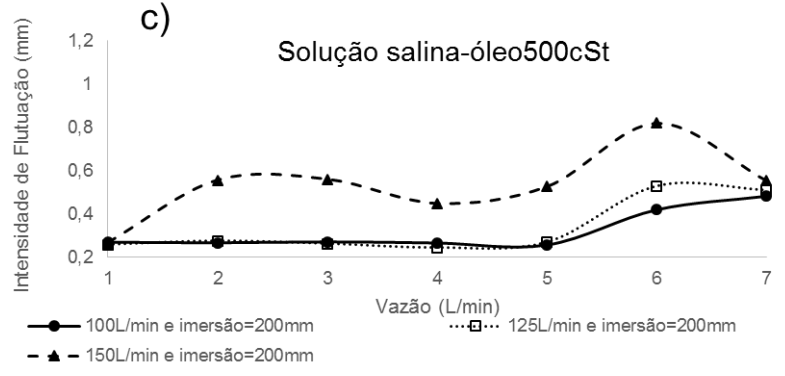

d)

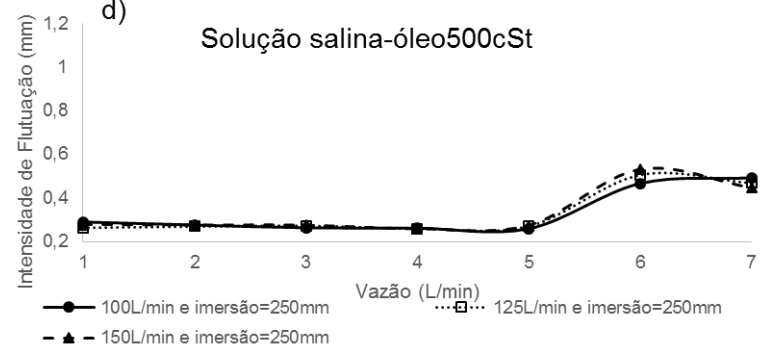

Figura 8 Comparação da intensidade de flutuação da superfície livre para as vazões e imersões ana-

lisadas. a) água-óleo $500 c S t$, b) água-óleo $200 c S t$ c) e d) solução salina-óleo 500cSt.

Também foram realizados testes de análise de oscilação superficial sem a camada de óleo. A figura 9 faz um comparativo da intensidade de oscilação da superfície livre entre os sistemas alimentados com água e solução salina. Nota-se que no primeiro caso a intensidade de oscilação é superior, principalmente na quina do flange oposto, na qual atinge valores superior a $1 \mathrm{~mm}$. Modo geral as oscilações são menores na presença de óleo, exceto na região do olho, região "6".
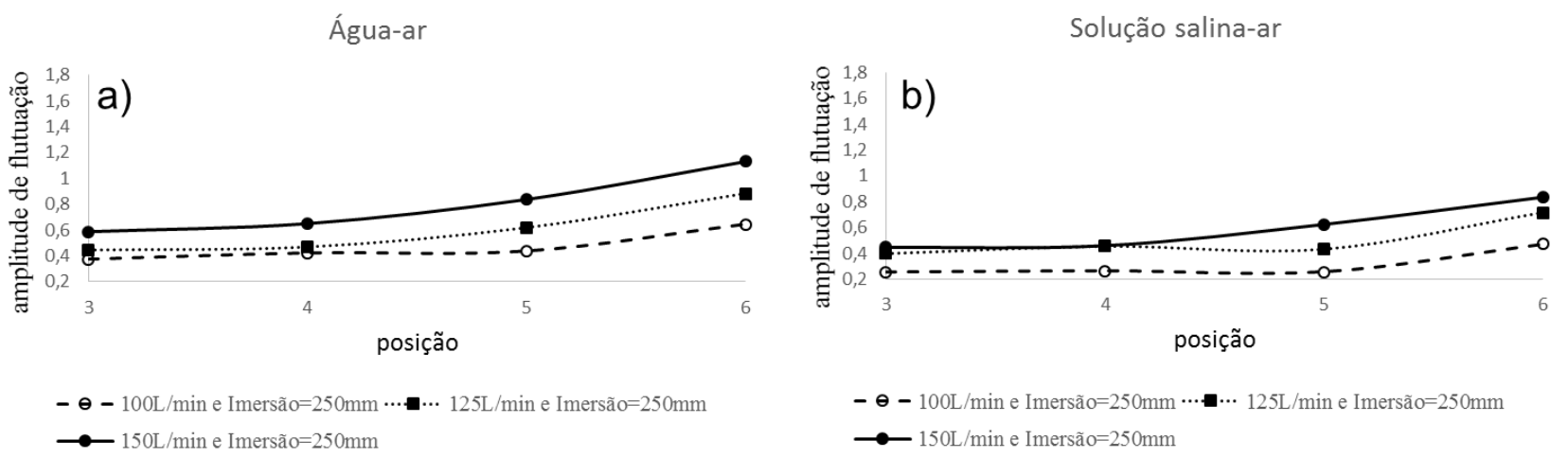

Figura 9 Comparação da intensidade de flutuação da superfície livre para as vazões de 100, 125 e 150L/min e imersão de 250mm. a) sistema água-ar e b) sistema solução salina-ar.

Ao verificar a superfície livre do molde, percebe-se uma boa concordância com os resultados de simulação computacional, conforme se exemplifica na figura 10 . Ela mostra a abertura do "olho" nas quinas do flange oposto. A fração volumétrica de óleo considerada para a isossuperfície foi de 0,1 . 


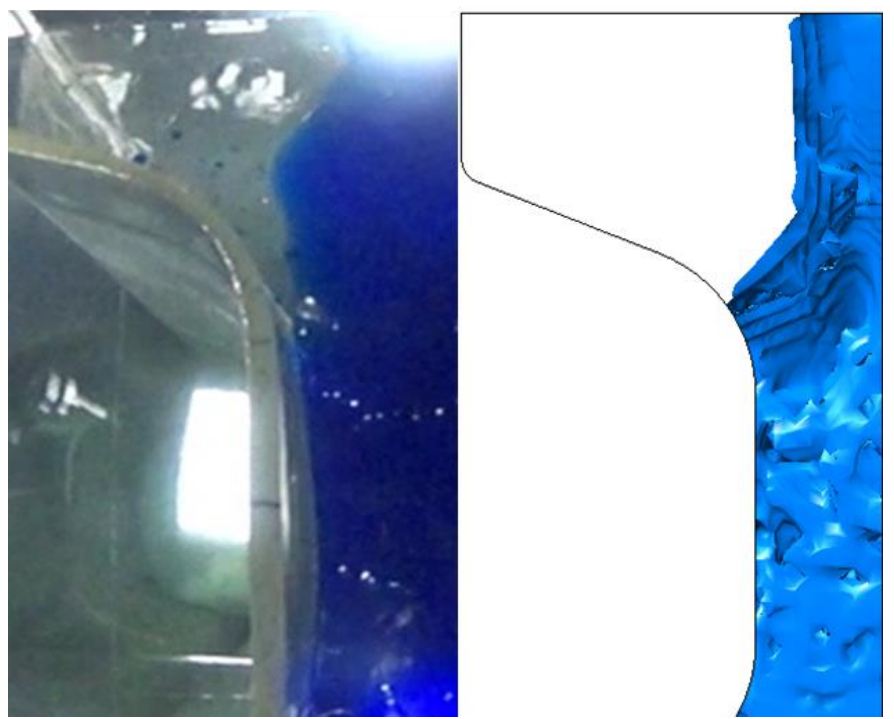

Figura 10 Avaliação da superfície livre a) simulação física, b) isossuperfície obtida via simulação computacional, fração volumétrica do óleo 500 cSt de 0,1 .

Foram avaliados os valores de velocidade resultantes ao longo da seção transversal a $250 \mathrm{~mm}$ da borda superior da porta de maior diâmetro. A velocidade nesta região varia significativamente em função da vazão de fluido no molde. Os valores de velocidade são maiores próximos às quinas do flange oposto à válvula, região em que se inicia o entranhamento manifestado pelo arraste do óleo para a parte central. Conforme se verifica na Figura 11. Pode-se observar também que para velocidades acima de $0,07 \mathrm{~m} / \mathrm{s}$ tem-se exposição da água ao ar, bem como entranhamento de óleo para o sistema água-óleo.

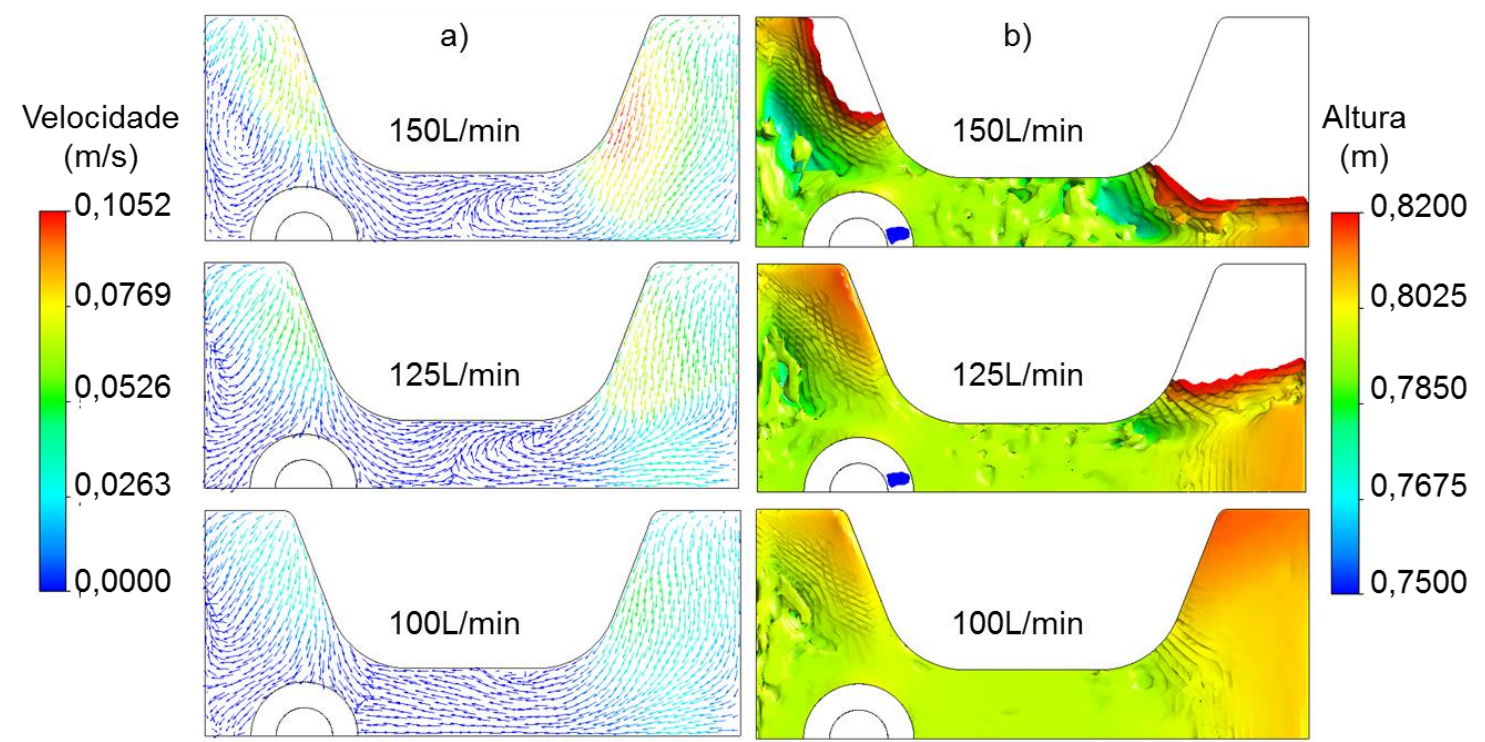

Figura 11 Sistema água-óleo1, profundidade de imersão da válvula submersa $250 \mathrm{~mm}$. a) Perfil de velocidade a $250 \mathrm{~mm}$ da borda superior da maior porta de saída. b) Isossuperfície com fração volumétrica de água 0,9 .

Quando se utilizou solução aquosa de $\mathrm{NaCl}$ pôde-se observar uma maior estagnação da superfície livre. De maneira geral, a intensidade de flutuação é também mais intensa próximo ao flange oposto e quando se reduz a profundidade de imersão para $200 \mathrm{~mm}$ (Figura 12), porém, os valores obtidos foram inferiores aos encontrados 
quando se utilizou água como emulante do aço líquido para a mesma profundidade de imersão (Figura 12). Além disto, o aumento de densidade do fluido inibe a abertura de olho, mesmo para imersões inferiores à utilizada no sistema água-óleo. Segundo Kasai et al. apud Suzuki et al [9] um aumento da densidade do fluido resulta em aumento da velocidade crítica necessária para a ocorrência de entranhamento.

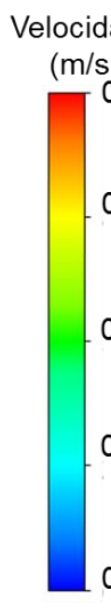

a)

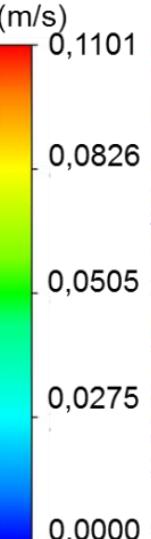

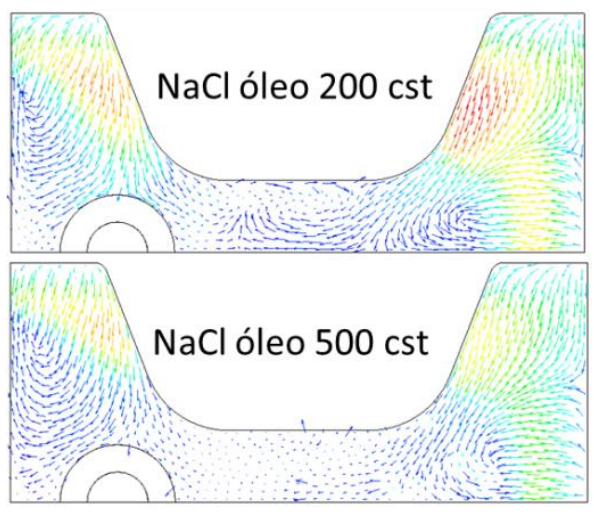

b)

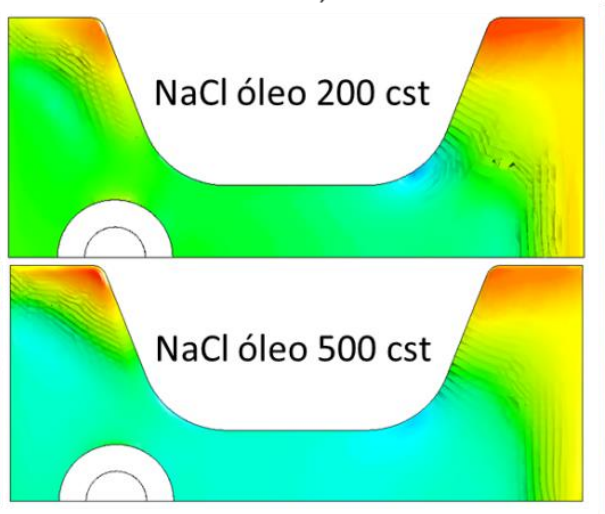

Altura

$(\mathrm{m})$

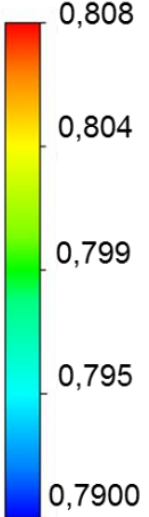

Figura 12 Influência da viscosidade no perfil de velocidade e no comportamento da interface solução salina-óleo, vazão de fluido $150 \mathrm{~L} / \mathrm{min}$ e profundidade de imersão da SEN igual $200 \mathrm{~mm}$. a) Perfil de velocidade a $200 \mathrm{~mm}$ acima da borda da maior porta da SEN e b) isossuperfície com 0,9 de solução $\mathrm{NaCl}$.

De acordo com a figura 13, tanto a redução da viscosidade do óleo quanto o aumento da densidade do fluido que simula o aço resulta em aumento da velocidade máxima na região analisada. O efeito da profundidade de imersão é quase desprezível sobre a velocidade máxima atingida.
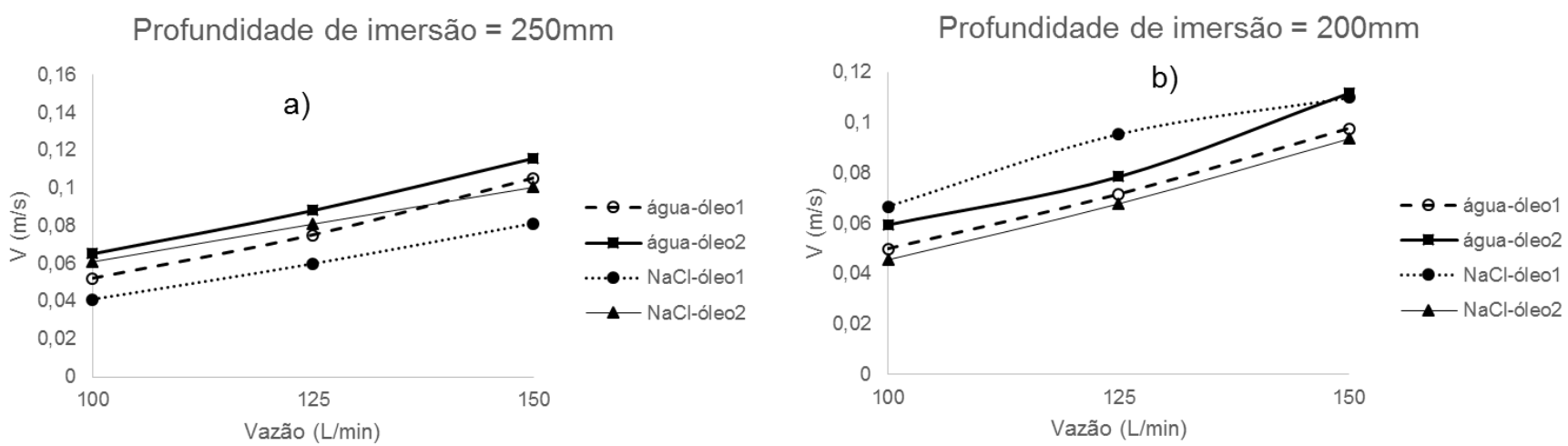

Figura 13 valores de velocidade máxima a uma distancia correspondente a profundidade de imersão da SEN em função das propriedades físicas dos fluidos utilizados: a) profundidade de imersão igual a $250 \mathrm{~mm}$, b) profundidade de imersão igual a $200 \mathrm{~mm}$. 


\section{CONCLUSÕES}

Os resultados obtidos forneceram as seguintes informações:

A redução da viscosidade do óleo resulta em aumento do arraste do mesmo no caso de maior velocidade de lingotamento.

Existe uma boa correlação entre o aspecto interfacial obtido por simulação matemática em regime permanente com a simulação física.

$\mathrm{O}$ aumento da densidade de $1000 \mathrm{~kg} / \mathrm{m}^{3}$ para $1170 \mathrm{~kg} / \mathrm{m}^{3}$ resultou em significativa alteração no comportamento interfacial.

Para o sistema contendo uma camada de óleo a intensidade de oscilação superficial é máxima na quina do flange oposto ao posicionamento da válvula. De maneira geral é nesta região onde se inicia a "abertura de olho".

A oscilação superficial na região do menisco diminui com o aumento na densidade do fluido.

Em nenhuma das condições avaliadas houve entranhamento de escória quando do aumento da densidade do fluido.

\section{Agradecimentos}

Os autores gostariam de agradecer FAPEMIG, à Coordenação de Aperfeiçoamento de Pessoal de Nível Superior (CAPES) pelo apoio financeiro, em especial pelas bolsas de pesquisa concedidas a W.V. Gabriel, G.L. Alves e J. J. M. Peixoto, respectivamente. 


\section{REFERÊNCIAS}

1 Hibbeler, L.C., Thomas, B. Mold Slag Entrainment Mechanisms in Continuous Casting Molds. Iron \& Steel Technology. 2013; 16, 121-136.

2 Cramb, A.W.,Chumg, Y., Harman, J., Sharan, A., Jimbo, I. The Slag-Metal interface and Associated Phenomena. Iron and Steelmaker. 1997; 24, 77-83.

3 Deng, A-y., Xu, L., Wang, E-g., He, J-c. Numerical Analysis of Fluctuation Behavior of Steel/Slag Interface in Continuous Casting Mold with Static Magnetic Field. Journal of Iron and Steel Research, International. 2014; 21, 809816.

4 Thomas, B.G. Modeling of Continuous Casting Defects Related to Mold Fluid Flow. Iron and Steel Technology. 2005; 3, 847.

5 Scheller, P.R e Hagemann, R. Model Investigations on Slag Entrainment in Continuous Casting. Metallurgy and Materials. 2012; Vol 57.p. 283-289.

6 Savolainen, J.; Fabritius, T e Mattila, O. Effect of Fluid Physical Properties on the Emulsification. ISIJ International. 2009; Vol. 49. No. 1, p. 29-36.

7 Harman, J.M e Cramb, A.W. A Study of The Effect of Fluid Physical Properties upon Droplet Emulsification. Steelmaking Conference Proceedings. Pittsburgh. 1996; Vol 79, p. 773-784.

8 Nadalon, J E A. Modelagem Numérica da Interface Metal-Escória em Moldes de Seção Circular sob o Efeito de Agitação Eletromagnética no Lingotamento Contínuo de Aço [Dissertação de Mestrado], Porto Alegre, Universidade Federal do Rio Grande do Sul, 2008.

9 Suzuki, M; Suzuki ,M; Nakada, M. Perspectives of Research on High-speed Conventional Slab Continuous Casting of Carbon Steels. ISIJ International. 2001; Vol. 41, No. 7, pp. 670-682. 